\title{
Succinoglycan Production Contributes to Acidic pH Tolerance in Sinorhizobium meliloti Rm1021
}

\author{
Justin P. Hawkins, Barney A. Geddes, and Ivan J. Oresnik ${ }^{\dagger}$ \\ Dept. of Microbiology, University of Manitoba, Winnipeg, R3T 2N2, Canada \\ Accepted 30 August 2017.
}

In this work, the hypothesis that exopolysaccharide plays a role in the survival of Sinorhizobium meliloti at low pH levels is addressed. When $S$. meliloti was grown at pH 5.75, synthesis of succinoglycan increased, whereas synthesis of galactoglucan decreased. Succinoglycan that was isolated from cultures grown at low $\mathrm{pH}$ had a lower degree of polymerization relative to that which was isolated from cultures grown at neutral $\mathbf{p H}$, suggesting that low-molecular weight (LMW) succinoglycan might play a role in adaptation to low $\mathrm{pH}$. Mutants unable to produce succinoglycan or only able to produce high-molecular weight polysaccharide were found to be sensitive to low $\mathrm{pH}$. However, strains unable to produce LMW polysaccharide were 10-fold more sensitive. In response to low $\mathrm{pH}$, transcription of genes encoding proteins for succinoglycan, glycogen, and cyclic $\boldsymbol{\beta}(1-2)$ glucans biosynthesis increased, while those encoding proteins necessary for the biosynthesis of galactoglucan decreased. While changes in pH did not affect the production of glycogen or cyclic $\beta(1-2)$ glucan, it was found that the inability to produce cyclic $\beta(1-2)$ glucan did contribute to $\mathrm{pH}$ tolerance in the absence of succinoglycan. Finally, in addition to being sensitive to low $\mathbf{p H}$, a strain carrying mutations in exoK and exs $H$, which encode the glycanases responsible for the cleavage of succinoglycan to LMW succinoglycan, exhibited a delay in nodulation and was uncompetitive for nodule occupancy. Taken together, the data suggest that the role for LMW succinoglycan in nodule development may be to enhance survival in the colonized curled root hair.

The availability of reduced nitrogen affects plant growth and productivity. In agriculture, symbiotic nitrogen fixation provides over 40 million tons of nitrogen to legume plants annually (Herridge et al. 2008). The utilization of biological nitrogen fixation is dependent on the ability of both the host plant and symbiotic rhizobia to be able to manage environmental stresses, such as soil acidity. Approximately $40 \%$ of the world's soil is affected by acidic conditions that could be prohibitive to the establishment of an effective symbiosis (Ferguson et al. 2013; von Uexküll and Mutert 1995). Increased acidity is known to negatively affect the growth of both symbiotic rhizobia and legume plants (Howieson et al. 1988; Lowendorf et al. 1981). Understanding how microbes can tolerate and survive in acidic conditions could contribute to improving plant yields in these environments.

The interaction of Sinorhizobium meliloti with alfalfa is used as a model system for studying symbiosis and nitrogen fixation

${ }^{\dagger}$ Corresponding author: Ivan J. Oresnik; E-mail: Ivan.Oresnik@umanitoba.ca

*The $\boldsymbol{e}$-Xtra logo stands for "electronic extra" and indicates that one supplementary figure and one supplementary table are published online.

(c) 2017 The American Phytopathological Society
(Geddes and Oresnik 2016). The developmental process is initiated upon recognition of a plant-secreted flavonoid by rhizobia in the rhizosphere. Recognition of flavonoids by $S$. meliloti leads to the induction of nod genes that encode the enzymes necessary to synthesize Nod factor (NF). NF is recognized by receptors on plant root hairs, resulting in a complex signal cascade in the plant (Oldroyd 2013). The end result of this cascade is twofold: i) the division of inner-cortical plant cells that form the nodule primordium and ii) the curling of plant root hairs (Jones et al. 2007). Root-hair curling is one of the earliest observable events associated with an effective symbiotic association. Detailed characterization of root-hair curling has shown that the curled root hair gives rise to an apoplastic space in which the bacteria form a microcolony. This compartment has been termed the curled colonized root hair (CCRH). Mutants of $S$. melilot Rm1021 unable to produce the exopolysaccharide (EPS) succinoglycan do not form effective symbiotic associations with the host plant, and become trapped in the CCRH (Cheng and Walker 1998a; Glazebrook and Walker 1989; Leigh et al. 1985).

S. meliloti is able to produce two main types of EPS, succinoglycan (EPS-I) and galactoglucan (EPS-II) (Skorupska et al. 2006). Either one of these polysaccharides must be produced for symbiotic establishment to be successful (Glazebrook and Walker 1989). Succinoglycan is comprised of a repeating polymer that is made up of an eight-sugar core consisting of one galactose and seven glucose units that can be decorated with succinyl, pyruvyl, and acetyl groups (Reinhold et al. 1994). Galactoglucan is a polymer that is made up of a repeating subunit that contains a single glucose linked to a galactose (Skorupska et al. 2006). EPS-II can be modified with acetyl and pyruvyl groups (Her et al. 1990). S. meliloti strain Rm1021 is unable to produce EPS-II under normal conditions, due to an insertion element in the regulator $\operatorname{expR}$. Strains that have an intact $\exp R$ gene are able to produce EPS-II and are termed $\exp R^{+}$(Pellock et al. 2000). Production of EPS-II can also be restored in Rm1021 under specific medium conditions (Mendrygal and González 2000; Oresnik et al. 1994).

The gene $e x o H$, which encodes the enzyme responsible for succinylation of EPS-I, has been shown to be necessary for symbiosis (Cheng and Walker 1998b; Leigh et al. 1987). In addition, exoH mutants have been shown to produce only highmolecular weight (HMW) EPS-I that cannot be cleaved into the low-molecular weight (LMW) form by the endoglycanases encoded by the genes exsH and exoK (York and Walker 1997). Strains lacking these endoglycanases have also been shown to not produce any LMW EPS-I (Mendis et al. 2016). Mutant strains carrying both endoglycanase mutations have been shown to be symbiotically active and result in only a minor decrease in overall plant growth compared with plants inoculated with the wild type (Mendis et al. 2016). This suggested that succinylation of EPS-I and not the LMW fraction is essential for symbiosis.

Many roles for EPS in symbiotic establishment have been suggested, including dampening of the plant immune response and 
protection from reactive oxygen species (Donati et al. 2011; Jones and Walker 2008; Lehman and Long 2013). More recently, EPS has also been shown to be directly involved in the symbiotic signaling process between Mesorhizobium loti and Lotus japonicus (Kawaharada et al. 2015). EPS has also been shown to be involved in tolerating physiological stress such as high salt, phosphate, and magnesium concentrations (Hawkins and Oresnik 2017; Mendrygal and González 2000; Miller-Williams et al. 2006). It has also hypothesized that EPS plays a role in $\mathrm{pH}$ stress tolerance (Cunningham and Munns 1984), though this has never been directly investigated.

Within the rhizosphere, low $\mathrm{pH}$ is a function of the plant roots secreting $\mathrm{H}^{+}$and organic acids that can decrease the $\mathrm{pH}$ by up to $2 \mathrm{pH}$ units (Faget et al. 2013). In addition, it has been shown that the cell wall of elongating roots is acidic and the development of root hairs is preceded by a further localized drop in $\mathrm{pH}$ at the site of initiation (Bibikova et al. 1998). It has also been shown that symbiotic compartments such as the bacteroid and the CCRH are acidic (Fedorova et al. 1999; Geddes et al. 2014; Pierre et al. 2013). This is prohibitive to the growth of $S$. meliloti Rm1021, since the strain cannot grow below a pH of 5.5 (Hellweg et al. 2009). In testing the response of $S$. meliloti to low $\mathrm{pH}$, a sudden $\mathrm{pH}$ shift from $\mathrm{pH} 7$ to $\mathrm{pH} 5.75$ has been shown to give rise to a complex transcriptional response that includes an increased transcription of genes encoding proteins necessary for the biosynthesis of EPS-I (Hellweg et al. 2009). However, the direct effect pH has on EPS production has not been determined, and the role EPS production may play in these environments remains unclear.

In this work, we address the hypothesis that EPS-I plays a direct role in $\mathrm{pH}$ tolerance and that this is an important determinant in establishing symbiosis with legume plants. We show that LMW
EPS-I facilitates survival at low $\mathrm{pH}$ and that strains that cannot produce LMW EPS-I show a delay in nodule establishment, and are less competitive for nodule occupancy.

\section{RESULTS}

EPS-I production increases and EPS-II decreases when $S$. meliloti is grown at low $\mathrm{pH}$.

We had previously shown that when a mutant unable to utilize galactose was grown in rhizobium minimal medium (RMM), containing both galactose and glycerol, it acidified its growth medium and produced EPS-I (Geddes et al. 2014). The growth of S. meliloti has been previously shown to be impaired at $\mathrm{pH} 5.5$ and only slightly affected at $\mathrm{pH} 5.75$ when grown on Vincent's minimal medium (VMM) utilizing glucose as a carbon source (Hellweg et al. 2009). We wished to further characterize the role $\mathrm{pH}$ had on EPS production, using RMM as a defined medium. When characterizing the growth of $S$. meliloti at different $\mathrm{pH}$ values, using RMM, we found that growth was the same as what had been previously published using VMM (data not shown). To be consistent with what had been previously determined, we chose to use a $\mathrm{pH}$ value of 5.75 to test the effect of medium acidification on EPS production.

To determine the effect of acidic $\mathrm{pH}$ on production of both EPS-I and EPS-II, mutants that are unable to produce either EPS-I (exoY55) or EPS-II (expA1) were utilized (Glazebrook and Walker 1989; Leigh and Lee 1988). Since an insertion element in the regulator $\exp R$ prevents the production of EPS-II in $\mathrm{Rm} 1021$, these alleles were transduced into a background that carried an intact $\exp R$ gene to restore production of galactoglucan (SRmD363). This yielded strains SRmD394 (expR ${ }^{+}$, exoY55) and SRmA777(expR $\left.{ }^{+}, \operatorname{expA1}\right)$.

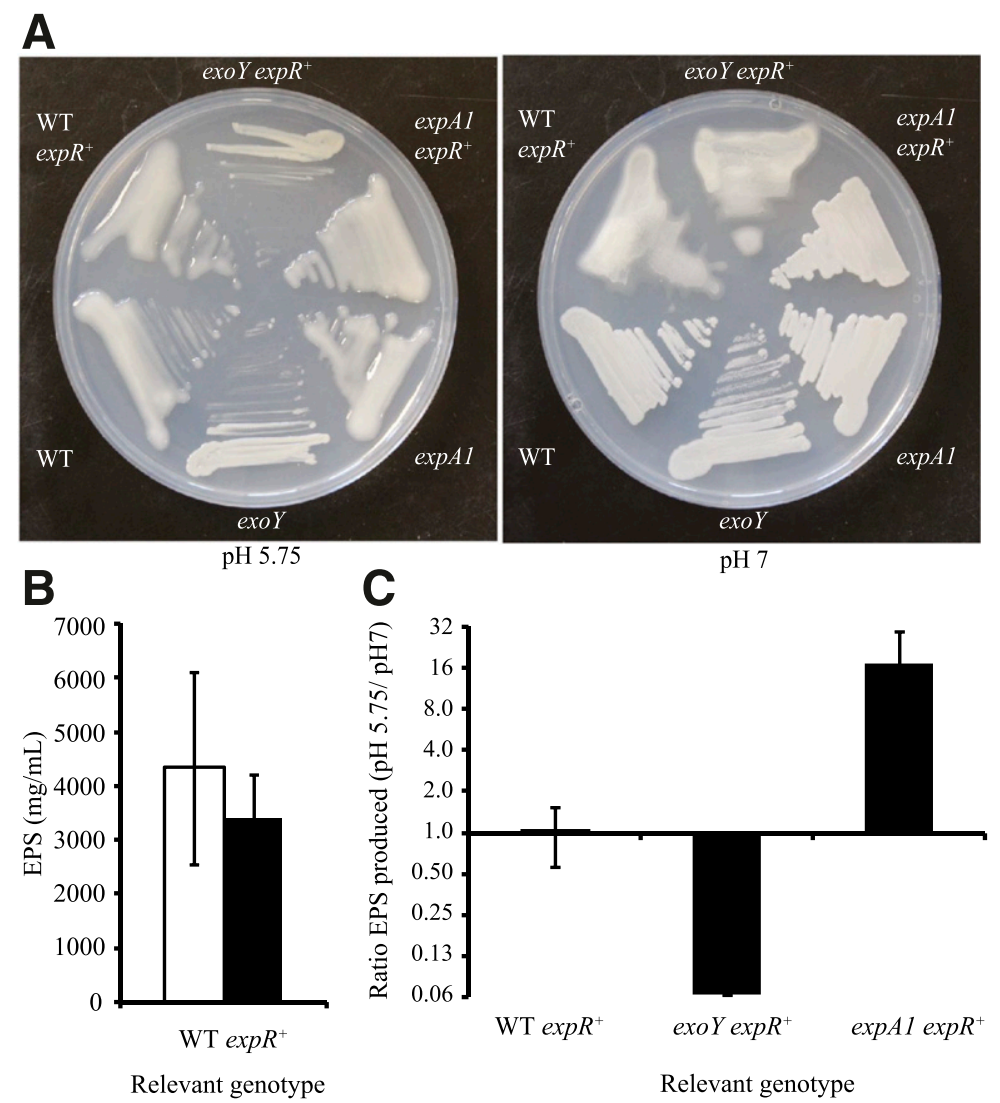

Fig. 1. Exopolysaccharide (EPS) production under neutral and acidic $\mathrm{pH}$. A, Visual mucoidy of strains grown at pH $5.75 \mathrm{or} \mathrm{pH}$ 7. B, EPS was precipitated from $50 \mathrm{ml}$ of culture supernatant and was dried and weighed after $72 \mathrm{~h}$ of growth. The white bar indicates EPS produced at pH 5.75; the black bar indicates EPS produced at $\mathrm{pH}$ 7. C, Precipitated EPS from strains grown at $\mathrm{pH} 7$ and $\mathrm{pH} 5.75$, expressed as a ratio of EPS produced at $\mathrm{pH} 5.75$ over that at $\mathrm{pH} 7 . \mathrm{All}$ numbers are an average of three independent biological replicates. EPS weights are normalized to the optical density at $600 \mathrm{~nm}$ of the culture. 
At pH 7, Rm1021 strains carrying either exoY or expA1 mutations were indistinguishable, on agar plates, with respect to mucoidy. In an $\exp R^{+}$background, the strains were visually mucoid except for the strain carrying the expA1 mutation (Fig. 1A). At pH 5.75, Rm1021 and SRmD363 were visibly mucoid and this was dependent on having an intact exoY gene. The strain capable of producing only EPS-II $\left(\operatorname{exoY}, \exp R^{+}\right)$was found to be dry at $\mathrm{pH}$ 5.75. These results suggested low $\mathrm{pH}$ repressed the production of EPS-II while increasing production of EPS-I. To confirm these results, the total amount of EPS produced by each strain was quantified. The amount of perceptible EPS did not change significantly in SRmD363 (wild type $\exp R^{+}$) at $\mathrm{pH} 5.75$ compared with that at $\mathrm{pH} 7$ (Fig. 1B and C). When production of EPS was determined for strains capable of only producing either

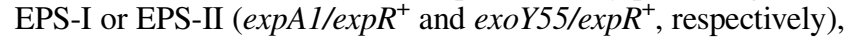
we observed increased EPS-I and decreased EPS-II production in response to low $\mathrm{pH}$. At neutral $\mathrm{pH}$, EPS-II biosynthesis was increased while EPS-I was decreased (Fig. 1C). This suggests that production of EPS-I is important under acidic conditions.

\section{A shift to acidic pH decreases}

the average chain length of EPS-I.

EPS-I consists of both HMW and LMW fractions. Changes in distribution between HMW and LMW succinoglycan can be detected by using the Lever assay to determine the concentration of reducing ends as a proportion of the total amount of EPS that has been synthesized (York and Walker 1998). To determine if the proportion of HMW and LMW fractions change, the concentration of reducing ends from EPS isolated from $\mathrm{Rm} 1021$ was determined at $\mathrm{pH} 7$ and at $\mathrm{pH}$ 5.75. As a control, we utilized $\mathrm{Rm} 7225$, which carries an exoH mutation and has been shown to produce only HMW EPS-I (Mendis et al. 2016).

The results show that both Rm1021 and the exoH mutant were found to produce approximately equivalent amounts of EPS-I at neutral $\mathrm{pH}$ (Table 1). At $\mathrm{pH} 5.75$, the total amount of EPS-I produced by Rm1021 was found to increase by $70 \%$, while the amount produced by $\mathrm{Rm} 7225$ only increased by $36 \%$. The concentration of reducing ends found in EPS-I from the wild type also increased when medium $\mathrm{pH}$ decreased. When expressed as a ratio, the data show that the EPS-I produced at a low $\mathrm{pH}$ is consistent with it being enriched with the LMW fraction (Table 1). We note that, although the estimated chain length for the exoH mutant strain is much higher than the wild type, the estimated chain length in this strain does change (Table 1).

\section{LMW EPS-I is involved in acidic pH stress tolerance.}

To determine if EPS-I or EPS-II play a direct role in allowing a cell to survive low $\mathrm{pH}$ conditions, mutants unable to produce either EPS-I or EPS-II were spotted onto medium buffered at $\mathrm{pH} 7$ or $\mathrm{pH}$ 5.75. Since the proportion of LMW EPS-I increases when $S$. melilolti was grown at a low $\mathrm{pH}$, we also tested if mutants unable to produce LMW EPS-I were impaired in $\mathrm{pH}$ stress tolerance. To accomplish this, both exoH (Rm7225) and exsH/exoK (Rm8826) mutant strains, which are incapable of producing LMW EPS-I, were tested for $\mathrm{pH}$ sensitivity. Inclusion of the double endoglycanase mutant strain let us examine if either the succinylation of EPS-I or the LMW fraction was necessary for $\mathrm{pH}$ tolerance.

The data from both the $\exp R^{-}$and $\exp R^{+}$backgrounds showed the same trends (Fig. 2; Supplementary Fig. S1). Strains that

Table 1. Effect of $\mathrm{pH}$ on EPS-I polymerization chain length

\begin{tabular}{|c|c|c|c|c|c|c|}
\hline \multirow[b]{2}{*}{ Strain (genotype) } & \multicolumn{3}{|c|}{ pH $7^{\mathbf{a}}$} & \multicolumn{3}{|c|}{ pH 5.75a } \\
\hline & EPS & Reducing ends $^{\mathbf{a}}$ & Ratio & $\mathbf{E P S}^{\mathbf{a}}$ & Reducing ends & Ratio \\
\hline Rm1021 (wild type) & $286 \pm 8$ & $17 \pm 1$ & 17 & $489 \pm 20 *$ & $46 \pm 8$ & $10^{*}$ \\
\hline $\operatorname{Rm} 7225($ exoH $)$ & $218 \pm 13$ & $1^{\mathrm{b}} \pm 0$ & 300 & $298 \pm 19^{*}$ & $5 \pm 1$ & $61 *$ \\
\hline
\end{tabular}

${ }^{\text {a }}$ EPS and reducing ends values are presented in milligrams per liter and are an average of three independent biological replicates that have been rounded to the nearest whole number. The ratio between total EPS-I and reducing ends is used as an indicator of the overall change in chain length of EPS-I.

b Actual value prior to value was 0.7 . This value was used to determine the ratio of EPS to reducing ends; an asterisk $(*)$ means the number is significant compared with $\mathrm{pH} 7$ values based on $P<0.05$ using Student's $t$ test.

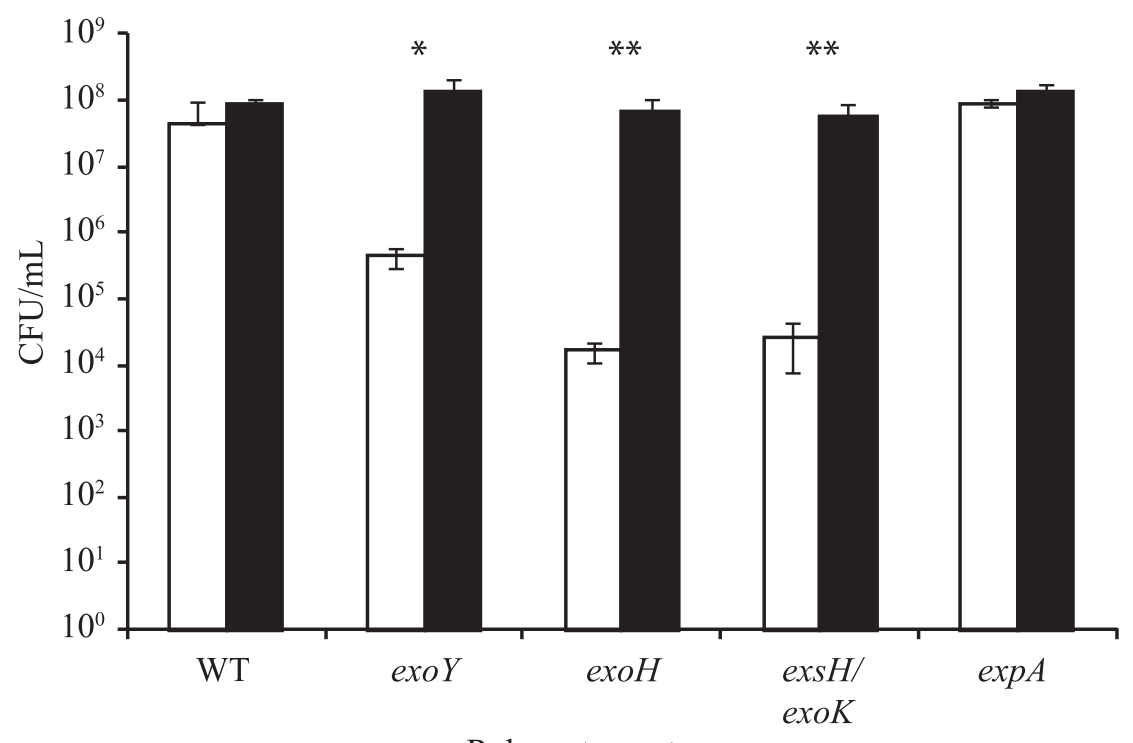

Relevant genotype

Fig. 2. EPS-I mutant sensitivity to acidic $\mathrm{pH}$ as calculated in CFU per milliliter from spot dilutions at pH 5.75 (white) and pH 7 (black). Results are an average of three independent biological replicates. One asterisk (*) indicates $P$ value $<0.05$, compared with wild type, two (**) indicate $P$ value $<0.05$, compared with exo $Y$ mutant values. 
carried an exoY mutation in either expR background showed a 1,000 -fold decrease in the number of colony forming units (CFU) when spotted onto medium at low $\mathrm{pH}$. The presence or absence of EPS-II did not affect overall survivability at low $\mathrm{pH}$. A strain carrying a mutation in $\mathrm{exoH}$ was found to be even more sensitive to low $\mathrm{pH}$ conditions than $\mathrm{S}$. meliloti strains unable to produce any EPS-I, resulting in a 10,000-fold decrease in CFU compared with wild type. The $\mathrm{pH}$ sensitivity of a strain carrying both $\operatorname{exs} H$ and exoK mutations was found to be the same as the exoH mutant strain at pH 5.75 (Fig. 2). This suggested that the LMW fraction of EPS-I and not the succinylation status of HMW EPS-I confers the ability for bacteria to survive on low $\mathrm{pH}$ medium.

\section{Induction of genes encoding polysaccharide biosynthesis components are altered in an exoY mutant.}

The result that a strain carrying an exoH mutation was more sensitive to acidic $\mathrm{pH}$ than a mutation in exoY was unexpected. It was hypothesized that this difference might be due to a redirection of carbon into other polysaccharides, which might also be involved in $\mathrm{pH}$ tolerance. To investigate this, the transcription

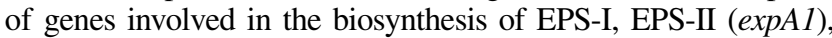
cyclic $\beta(1-2)$ glucans $(n d v B)$, glycogen $(g \lg A 1)$, lipopolysaccharide
(LPS) ( $k d s B 2, l p s L$, and $l p s B)$, and capsular polysaccharide (KPS) $(r k p A, k d s B 2)$ was determined in either the wild type or an exoY mutant strain (Becker et al. 1997; Dylan et al. 1990; Kereszt et al. 1998; Müller et al. 2009; Wang et al. 2007).

The results showed that $S$. meliloti responds to growth in acidic conditions through increased transcription of genes that encode determinants for both HMW and LMW EPS-I production (Fig. 3; Table 2). In addition, both exoR and $c h v I$, encoding proteins that have been shown to regulate EPS-I biosynthesis, were found to be upregulated. Consistent with our EPS quantification (Fig. 1C), expA1 was found to be downregulated under acidic conditions. In addition, transcription of $g \lg A 1$ and $n d v B$ were also increased. Transcription of representative genes encoding determinants for LPS and KPS biosynthesis were found to be unaffected by acidic conditions (Table 2).

When the same analysis was carried out in an exoY mutant background, it was found that the transcription of most genes involved in EPS-I biosynthesis were greater at $\mathrm{pH} 5.75$ than when grown at $\mathrm{pH}$ 7. Since primers used for detecting the transcription of exoY were positioned upstream of the Tn5 insertion in the mutant strain, we still observed transcription of exoY in Rm7055 (Fig. 3). The regulators chvI and exoR were no

\section{Glucose}
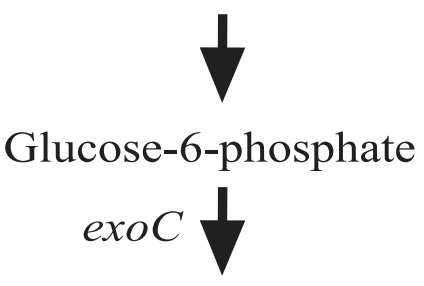

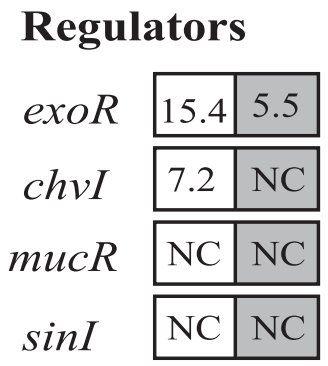

EPS modification

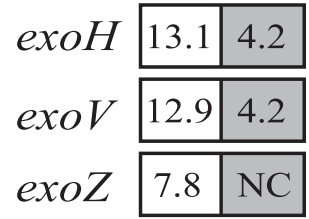

\section{Glucose-1-phosphate}

exoN

UDP-Glucose

exoB $\mathbf{5}$\begin{tabular}{|l|l|}
\hline 5.7 & 2.0 \\
\hline
\end{tabular}

UDP-Galactose

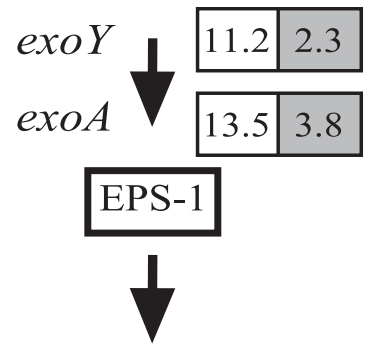

HMW EPS-I

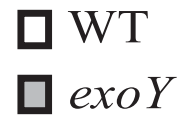

exoY

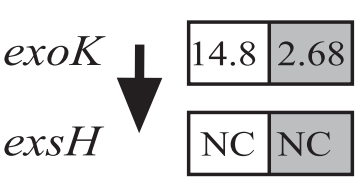

LMW EPS-I

Fig. 3. Changes in gene expression due to acidic medium. Data expressed as $2^{\Delta \Delta \mathrm{Ct}}$ and represents fold change in gene expression at $\mathrm{pH} 5.75 \mathrm{over} \mathrm{pH} 7$. The gene SMc00128 was included in the experiment as an internal control. All numbers represent an average of three independent biological replicates. Standard deviations for all numbers are within $1 \mathrm{Ct}$ (cycle threshold). $\mathrm{NC}=$ no change. 
longer observed to have increased transcription at $\mathrm{pH} 5.75$. The transcription of exoN, which codes for the protein necessary to catalyze formation of UDP-glucose from glucose-1-phosphate, was found to decrease twofold. This enzyme is of importance because it serves as a branching point between glycogen synthesis and other polysaccharides. Additionally, of the genes analyzed for synthesis of other polysaccharides, only $\operatorname{glg} A 1$ was observed to be increased in transcription when grown at acidic $\mathrm{pH}$ compared with neutral $\mathrm{pH}$ in the exoY background. Taken together, this suggested that the carbon that would normally be utilized to produce EPS-I may be directed toward the synthesis of glycogen in the absence of EPS-I production.

\section{Production of glycogen is affected}

by the ability to produce EPS-I.

The ability to produce both glycogen and cyclic $\beta(1-2)$ glucans has been linked with changes in EPS-I biosynthesis (Dylan et al. 1990; Wang et al. 2007). To determine if the ability to produce EPS-I affects the intracellular accumulation of glycogen or cyclic $\beta(1-2)$ glucans, both polysaccharides were quantified in strains carrying mutations in either exoY or exoH and were compared with wild-type production. The data showed that a mutation in exoY led to greater amounts of glycogen in both low and neutral $\mathrm{pH}$ conditions (Fig. 4A). However, cyclic $\beta(1-2)$ glucans isolated from cells grown at either $\mathrm{pH}$ or in either mutant background did not show any significant changes when compared with wild-type concentrations (Fig. 4B).

\section{Cyclic $\beta(1-2)$ glucan production plays an auxillary role in $\mathrm{pH}$ tolerance.}

While neither intracellular polysaccharide was shown to be influenced by $\mathrm{pH}$ at the time point measured, $\mathrm{pH}$ was still shown to influence the transcription of both $n d v B$ and $g \lg A l$. This may indicate the importance of these genes in response to acidic $\mathrm{pH}$. To determine if either glycogen or cyclic $\beta(1-2)$ glucans play a role in surviving low $\mathrm{pH}$, the exo $Y: \operatorname{Tn} 5$ mutation was transduced into strains Rm1 $1482(\triangle g \lg A 1, g \lg A 2:: \Omega \mathrm{SpSm})$ and SRmD377 ( $n d v B:: \operatorname{Tn} 5-233)$ to create strains SRmD455 and SRmD456, respectively. Each strain was then tested for sensitivity to acidic $\mathrm{pH}$. Strains containing either the $n d v B$ mutation or the $\triangle g \lg A 1 \Omega \mathrm{SpSm}:: g \lg A 2$ mutations were not compromised in their ability to survive at pH 5.75 (Fig. 5). The $n d v B /$ exoY double mutant was found to have an increased sensitivity to acidic $\mathrm{pH}$, while SRmD455 still showed the same $\mathrm{pH}$ sensitivity as an exoY mutant strain. Overall, the data showed that,

Table 2. Additional quantitative reverse transcription-polymerase chain reaction results

\begin{tabular}{llcc}
\hline & & \multicolumn{2}{c}{ Fold change $^{\mathbf{a}}$} \\
\cline { 3 - 4 } Gene & \multicolumn{1}{c}{ Function } & Rm1021 & Rm7055 \\
\hline exoF & Polysaccharide export & 10.85 & 3.0 \\
exoX & Posttranscriptional regulator & 2.0 & NC \\
exoD & Putative transmembrane protein & 5.94 & NC \\
rkpA & Putative fatty acid synthase & NC & NC \\
$k d s B 2$ & CMP-Kdo transferase & NC & NC \\
lpsB & LPS mannosyltransferase & NC & NC \\
lpsL & UDP-glucuronate 5' -epimerase & NC & NC \\
expE1 & ABC transporter & 0.4 & NC \\
expE2 & Glycosyltransferase & NC & NC \\
wggR & Transcriptional activator & NC & NC \\
flbT & Putative flagellar repressor protein & 0.18 & 0.12 \\
flgB & Flagellar protein & NC & 0.14 \\
\hline
\end{tabular}

${ }^{a}$ Fold change in gene expression. Data are expressed as $2^{\Delta \Lambda \mathrm{Ct}}$, representing fold expression of strains grown in medium buffered at $\mathrm{pH} 5.75$ over $\mathrm{pH} 7$. SMc00128 is used as an internal control. The table represents an average of three independent replicates with standard error within one cycle. $\mathrm{NC}=$ no change. while the inability to produce cyclic $\beta(1-2)$ glucans does not produce a $\mathrm{pH}$ sensitive phenotype, when combined with an exoY mutant background, the strain becomes impaired in $\mathrm{pH}$ tolerance to the same degree as an exoH mutant.

A double endoglycanase mutation leads

to a delay in nodule formation and is ineffective

in competition for nodule occupancy.

Acidic $\mathrm{pH}$ has been shown to be present in a number of plantderived compartments during the nodulation process (Fedorova et al. 1999; Pierre et al. 2013). The finding that strains that acidified their growth medium were more competitive for nodule occupancy in an EPS-I-dependent manner suggested that the ability to adapt to a low $\mathrm{pH}$ environment is necessary for efficient nodulation (Geddes et al. 2014). While most strains that carry a mutation in genes necessary for EPS-I biosynthesis in S. meliloti have severe symbiotic phenotypes (Becker et al. 1993a and b; Leigh et al. 1985), plants inoculated with the exsH/exoK mutant strain only exhibit a slight decrease in overall plant growth (Mendis et al. 2016). If adaptation to acidic $\mathrm{pH}$ is a determinant in symbiotic establishment, it was reasoned that $\mathrm{pH}$-sensitive strains should be delayed in nodule formation and, possibly, be also uncompetitive for nodule occupancy.

The results show that, although plants inoculated with the double endoglycanase mutant achieved $100 \%$ nodulation, there

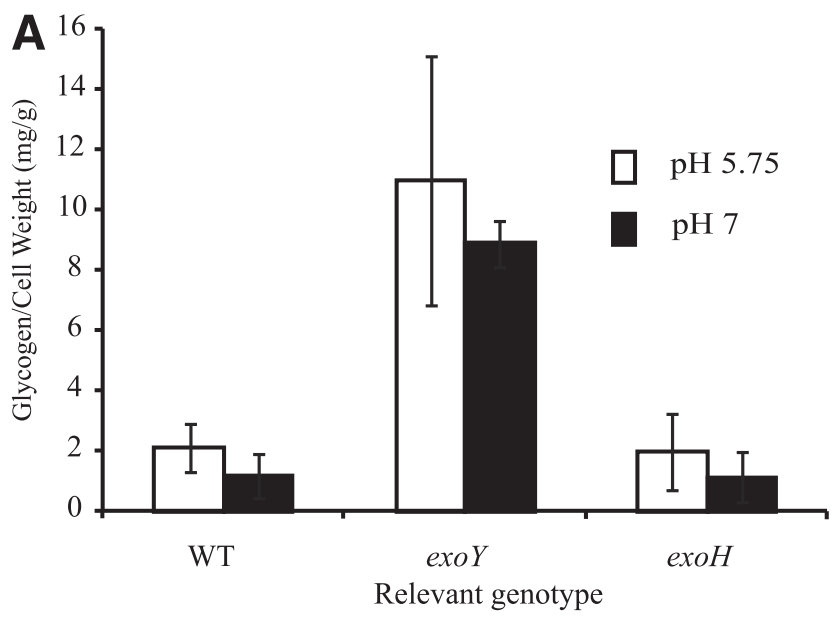

B

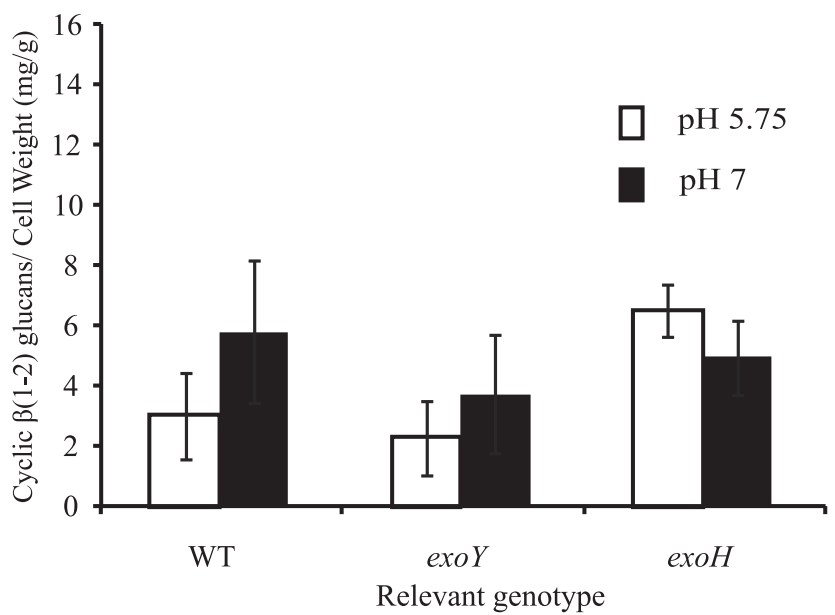

Fig. 4. Production of glycogen and cyclic $\beta(1-2)$ glucans at $\mathrm{pH} 7$ and $\mathrm{pH}$ 5.75. Each polysaccharide was extracted after 3 days growth in mannitol/glutamate/salts at the indicated $\mathrm{pH}$. Both $\mathbf{A}$, glycogen and $\mathbf{B}$, cyclic $\beta(1-2)$ glucans were quantified using the anthrone assay. Results are an average of three independent biological replicates. 
was a change in the rate of nodule formation (Fig. 6A). Initial appearance of nodules occurred at about 5 days postinoculation for the wild type under our growth conditions, whereas the exsH/exoK mutant strain was consistently delayed by at least 1 day (Fig. 6A). This delay became more prominent when plants reached $50 \%$ nodulation; while plants inoculated with Rm1021 were $50 \%$ nodulated after 8 days, plants inoculated with the mutant achieved this proportion at 11 days (Fig. 6B).

When this strain was tested for its ability to compete for nodule occupancy, it was found that the exsH/exoK mutant was severely impaired in its ability to compete with the wild type for nodule occupancy (Fig. 6C). Consistent with previous results (Mendis et al. 2016), the ability of plants inoculated with the exsH/exoK mutant to accumulate dry matter under nitrogenlimiting conditions was found to be slightly impaired compared with wild type-inoculated plants (Fig. 6D). These data are consistent with the hypothesis that the inability of the double endoglycanase mutant to tolerate acidic $\mathrm{pH}$ plays a role in early nodule formation and its ability to compete for nodule occupancy.

\section{DISCUSSION}

In this work, we addressed the hypothesis that EPS-I plays a role in allowing $S$. meliloti to survive a low $\mathrm{pH}$ environment. By using well-characterized $S$. meliloti mutant strains that produce either EPS-I, EPS-II, or both polysaccharides, we provide direct evidence that EPS-I and EPS-II production are regulated by the $\mathrm{pH}$ of the medium (Fig. 1A and C). These observations were corroborated through quantitative reverse transcription-polymerase chain reaction (qRT-PCR) expression data of key genes that encode enzymes necessary for biosynthesis of each EPS (Fig. 3; Table 2). Although these results are consistent with previous work, we note that changes in gene expression of $\operatorname{expA1,} g \lg A 1$, and $n d v B$ have not been previously reported. While our results are from cells exposed to each $\mathrm{pH}$ for $24 \mathrm{~h}$, previous work focused on transcriptional changes that occurred after an hour following a sudden $\mathrm{pH}$ change. We note that, although this work found a change in expression of $g \lg A 2$ (Hellweg et al. 2009), this gene has been shown to not be involved in glycogen synthesis (Wang et al. 2007).

The response of $S$. meliloti to low $\mathrm{pH}$ is largely mediated through the ExoR/ExoS/ChvI (RSI) system, which has been shown to be upregulated due to acidic $\mathrm{pH}$ in $S$. meliloti (Hellweg et al. 2009). The RSI system is well-studied for its ability to regulate the production of EPS-I and flagella (Cheng and Walker 1998b; Heavner et al. 2015). ExoS acts as a sensor kinase that directly phosphorylates the response regulator ChvI in response to a yet-unknown signal (Cheng and Walker 1998b; Yao et al. 2004). This system is regulated through direct binding of the repressor ExoR to ExoS in the periplasm (Chen et al. 2008). Homologs of this system in Agrobacterium tumefaciens have been shown to be involved in gene regulation due to acidic $\mathrm{pH}$ and it has been suggested that acidity is a key signal in establishing virulence with plants (Li et al. 2002). Further study of the RSI regulon in A. tumefaciens and S. meliloti has revealed that at acidic $\mathrm{pH}$ the repressor ExoR is degraded, resulting in increased EPS-I synthesis (Heckel et al. 2014; Lu et al. 2012). Mutants lacking $c h v I$ in $S$. meliloti have also been shown to be sensitive to acidic pH (Wang et al. 2010). Combined with our results, it is likely this is due to the inability of the $c h v I$ mutant to produce EPS-I.

A shift to acidic $\mathrm{pH}$ also influences the degree of polymerization of EPS-I to favor lower molecular weight forms (Table 2). Unexpectedly, a decrease in chain length polymerization was also observed in the exoH mutant strain that produces nonsuccinylated EPS-I, which cannot be cleaved by the exsH/exoK endoglycanases (Table 1). The degree of polymerization of EPS-I has been shown to be under control of ExoP/ ExoT/ExoQ, in addition to post-processing cleavage by ExsH and ExoK (Becker et al. 1995; González et al. 1998). The transcription of exoP, exoT, and exo $Q$ have also been shown to increase under acidic conditions (Hellweg et al. 2009). This may explain why we observed a significant difference of polymerization in exoH mutant strain. Although the degree of polymerization changed, it did not appear to be great enough to have a physiological effect.

The exact mechanism that LMW EPS-I production plays in $\mathrm{pH}$ tolerance is still unknown. The production of this form of succinoglycan could simply provide a physiological barrier, or the increased amount of reducing ends may create a natural buffering system. However, the $\mathrm{pK}_{\mathrm{a}}$ value of EPS-I from S. meliloti was determined through protonation of its carboxylic groups and was shown to be pH 3.8 (Szewczuk-Karpisz et al. 2014). Although the $\mathrm{pK}_{\mathrm{a}}$ gives some insight into the biophysical properties of EPS-I,

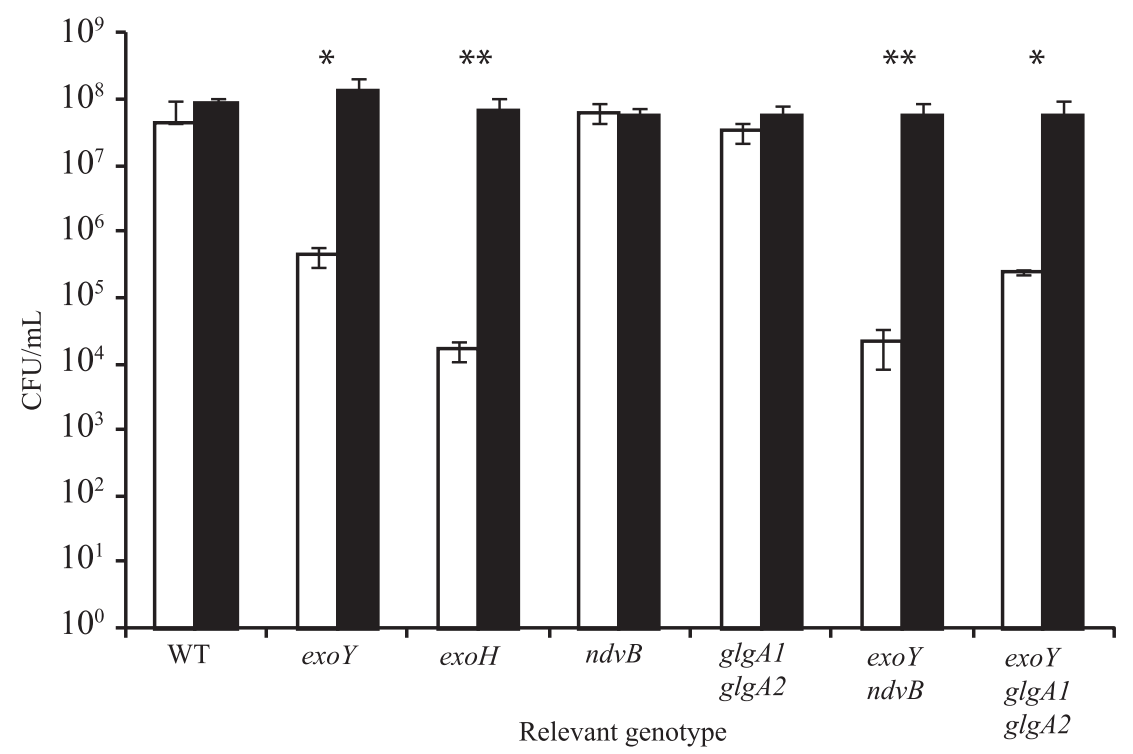

Fig. 5. Role of cellular polysaccharides in $\mathrm{pH}$ tolerance. Calculated in $\mathrm{CFU}$ per milliliter from spot dilutions at $\mathrm{pH} 5.75$ (white) and pH 7 (black). Results are an average of three independent biological replicates. One asterisk $(*)$ indicates $P$ value $<0.05$, compared with wild type, two (**) indicate $P$ value $<0.05$, compared with exoY mutant values. 
it is unclear if this could be playing a role, since the buffering capacity of EPS-I at pH 5.75 should be negligible. It has also been shown that production of EPS and its localization to the surface of Rhizobium leguminosarum bv. trifolii, results in a greater electronegative charge, increased hydrophobicity, and changes in the apparent dissociation constant for the cell (Cieśla et al. 2016). It is possible that cell-surface modification from EPS production in $S$. meliloti may have similar effects that play into acidic $\mathrm{pH}$ tolerance. While our results showed the inability to produce LMW EPS-I is detrimental to survival at low pH (Fig. 2), further studies are necessary to determine if increased production of the LMW fraction of EPS-I could offer increased acidic $\mathrm{pH}$ tolerance. Future investigation is also still needed to determine why a mutant unable to produce LMW EPS-I is more sensitive to acidic $\mathrm{pH}$ than a mutant not producing any EPS-I at all.

The involvement of cyclic $\beta(1-2)$ glucans in $\mathrm{pH}$ tolerance when EPS-I is absent was unexpected, since intracellular concentrations were not affected under the conditions that were tested (Fig. 4B). Previous work has shown that suppression of the symbiotic phenotype associated with an $n d v B$ mutant implicates EPS-I-associated genes (Nagpal et al. 1992), suggesting that EPS-I and cyclic $\beta(1-2)$ glucans may play complementary physiological roles. If this is the case, cyclic $\beta(1-2)$ glucans may also provide a buffering system or a physiological barrier when accumulated in the periplasm. The observation that loss of cyclic $\beta(1-2)$ glucan production on its own does not result in a change in $\mathrm{pH}$ sensitivity also further suggests that these two polysaccharides play a similar physiological role. The possibility does exist that an increased amount of cyclic $\beta(1-2)$ glucans could be excreted into medium to provide increased $\mathrm{pH}$ tolerance, though this has yet to be investigated.

The production of EPS represents a large carbon sink for $S$. meliloti. Our results are consistent with the hypothesis that carbon can be redirected to another polysaccharide such as glycogen, in the absence of EPS-I production. While the accumulation of glycogen did not affect $\mathrm{pH}$ tolerance between the exoY and exoH mutant strains, the data clearly demonstrate that carbon that is not used for synthesis of EPSs in an exoY mutant can affect the concentration of other macromolecular compounds.

In $S$. meliloti, both glycogen and poly-hydroxybutyrate (PHB) are produced as major carbon storage compounds under growth-limiting conditions (Zevenhuizen 1981). In contrast, EPSs are generally produced after accumulation of these intracellular polysaccharides (Zevenhuizen 1981). The carbon flow between PHB and glycogen is highly interconnected and has been shown to be under similar regulatory control (Dunn et al. 2002; Povolo and Casella 2000). It has determined that the loss of PHB synthesis results in a decrease of EPS-I synthesis, leading to the hypothesis that carbon stored in PHB is used for the production of other polysaccharides during symbiosis (Aneja et al. 2004; Wang et al. 2007). To our knowledge, this may be the first report to demonstrate that the loss of EPS-I production influences either one of these major carbon stores. It is of note that it has been recently shown that continual growth at low $\mathrm{pH}$ results in a decreased accumulation of $\mathrm{PHB}$, which may be correlated with the increase in EPS-I production (Draghi et al. 2017).

Succinoglycan has been inextricably linked with nodule development in S. meliloti (Leigh et al. 1985). Although it has been shown to be important, its exact role has never been elucidated. More recently, it has been shown in Lotus japonicus that defects in EPS could be suppressed by mutations in a LysM-type receptor kinase that can directly bind EPS (Kawaharada et al. 2015). In $S$. meliloti, it has been shown that the succinylation of EPS-I and not the LMW form of the EPS-I was an important determinant for allowing the establishment of an effective symbiosis. Taken together, these strongly suggest that EPS-I can be a signal that is used
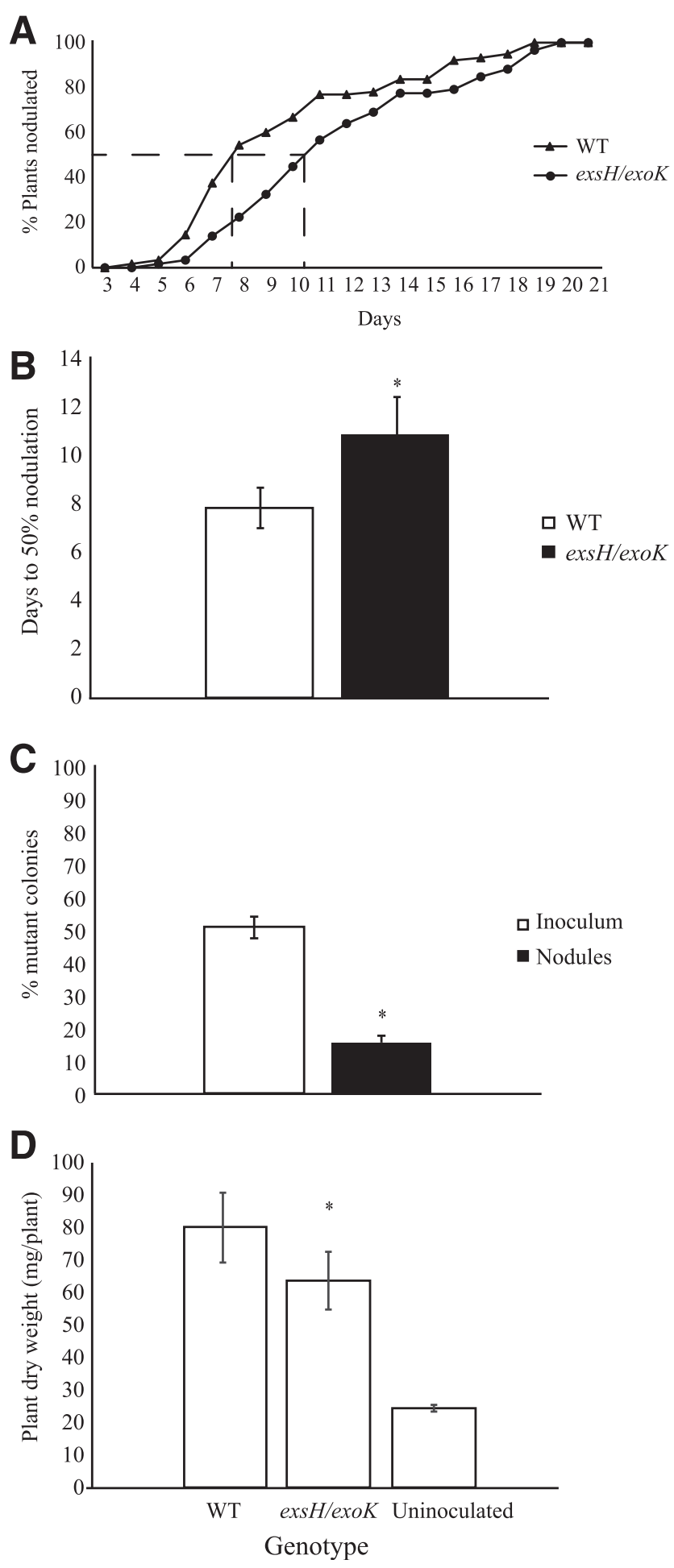

Fig. 6. Symbiotic phenotypes of an exsH/exoK mutant strain. A, Percentage of plants nodulated over time after inoculation with Rm1021 or Rm8826. Data are the sum of over 50 plants over four biological replicates. The average standard deviation of each point is 8 and $9 \%$, respectively, for Rm1021 and Rm8826. B, Average number of days postinoculation before $50 \%$ of plants became inoculated. C, Rm8826 competed against Rm1021 for nodule occupancy of Medicago sativa. Data are presented as the average proportion of Rm8826 found in the inoculum (white) and isolated from nodules (black). Data are the average of three independent biological replicates. D, Average dry weight per $M$. sativa plant inoculated with Rm1021 or Rm8826. Data are an average of three independent biological replicates consisting of 10 plants each. For B, C, and D, significance was determined using Student's $t$ test. One asterisk $(*)$ indicates $P<0.05$. 
to initiate the formation of an infection thread. While this may represent a strong 'checkpoint' in the process, we propose that LMW EPS-I plays a role that governs the efficiency of the overall nodulation process.

Fluorescent microscopy utilizing acidotropic dyes has clearly shown that the bacteria encounter low $\mathrm{pH}$ environments during the initial colonization of the root hair (Geddes et al. 2014) as well as when the bacteria are actively fixing nitrogen (Fedorova et al. 1999). Our data suggest that the inability to convert HMW EPS-I to the LMW form results in a sensitivity to low $\mathrm{pH}$ as well as a delay in nodule development (Figs. 2 and 6A). Importantly, the nodules that were formed by the double endoglycanase mutant appeared to be normal, yet the plants had accumulated less dry matter (Fig. 6D), presumably due to less nitrogen being reduced by the microsymbiont. Although we attempted to repeat these experiments at a low $\mathrm{pH}$, we were unsuccessful due to poor nodulation. We note that it has been previously shown that roothair development is adversely affected by the $\mathrm{pH}$ of the growth medium (Bibikova et al. 1998). The reduction in the amount of dry matter accumulated by the double endoglycanase mutant can either be due to the delay in nodule formation, which also leads to a delay in the maturation of nitrogen-fixing bacteroids, or that the nitrogen-fixing bacteroids are less efficient due to low $\mathrm{pH}$ found in the symbiosome. These two suggestions may not be mutually exclusive.

The results of this study, together with the supporting literature, suggests that $\mathrm{pH}$ plays a strong role in shaping the efficiency of early host-symbiont interaction. Once the colonization of the curled root hair occurs, the compartment becomes acidified (Geddes et al. 2014). Acidification leads to an increase of succinoglycan production via exoR/exoS/chvI signaling (Chen et al. 2008; Hellweg et al. 2009). The synthesized EPS plays two roles; the succinylated EPS-I works as a signal, which is critical for infection thread development (Jones et al. 2007; Kawaharada et al. 2015), whereas the LMW fraction enhances the ability of the bacteria to survive in the CCRH. If acidification and, thus, EPS synthesis occurs more rapidly, this can lead to a more rapid progression of the bacteria from the CCRH to the formation of visible nodules (Geddes et al. 2014; Jones 2012). The inability to make LMW succinoglycan would decrease the bacterial viability in the CCRH and lead to a delay, but not an abortion, of infection thread formation and visible nodule development (Fig. 6). The visualization of activity from an exoF::TnphoA fusion in the invasion zone of nodules also suggests that succinoglycan may play a role later in nodule development (Reuber et al. 1991). It is pertinent to note that there is ample evidence suggesting that actively fixing symbiosomes are acidic compartments and that exo genes are not highly expressed bacteroids (Fedorova et al. 1999; Reuber et al. 1991). It is also noteworthy that other mechanisms of tolerating low $\mathrm{pH}$ have been described for S. meliloti (Chen et al. 1993; Tiwari et al. 1996), suggesting that LMW succinoglycan may not play a major role at later stages of symbiosis.

Overall, our observations support the hypothesis that production of LMW EPS-I is involved in tolerating acidic $\mathrm{pH}$ stress and that this affects symbiosis. The precise mechanism of how EPS-I fulfils this role is currently unclear. Further work to define how EPS-I biosynthesis responds to environmental shifts by measuring transcription and translation as well as metabolic pools may provide useful data to formulate hypotheses that can be used to address this question and are the focus of future studies.

\section{MATERIALS AND METHODS}

\section{Bacterial strains, plasmids, and media.}

Bacterial strains and plasmids created and used in this work are listed in Table 3. S. meliloti was grown at $30^{\circ} \mathrm{C}$ on either LuriaBertani or tryptone yeast extract as complex medium (Sambrook et al. 1989). RMM (Broughton et al. 1986) or mannitol/glutamate/salts (MGS) (Mendrygal and González 2000) was used as a defined medium. Mannitol was filter-sterilized and was used at a final

Table 3. Bacterial strains and plasmids

\begin{tabular}{|c|c|c|}
\hline Strain or plasmid & Genotype or phenotype ${ }^{a}$ & Source or reference \\
\hline \multicolumn{3}{|c|}{ Sinorhizobium meliloti } \\
\hline Rm1021 & $\mathrm{SU} 47 \mathrm{str}-21, \mathrm{Sm}^{\mathrm{r}}$ & Meade et al. 1982 \\
\hline SRmA363 & $\mathrm{Rm} 1021 \exp ^{+}, \mathrm{Sm}^{\mathrm{r}}$ & Miller-Williams et al. 2006 \\
\hline $\operatorname{Rm} 7055$ & $\mathrm{Rm} 1021$ exoY55::Tn5, $\mathrm{Sm}^{\mathrm{r}}, \mathrm{Nm}^{\mathrm{r}}$ & Leigh et al. 1985 \\
\hline SRmD394 & SRmA363 exoY55::Tn $5, \mathrm{Sm}^{\mathrm{r}}, \mathrm{Nm}^{\mathrm{r}}$ & This work \\
\hline SRmA775 & $\mathrm{Rm} 1021 \exp A 1:: \mathrm{Tn} 5, \mathrm{Sm}^{\mathrm{r}}, \mathrm{Nm}^{\mathrm{r}}$ & This work \\
\hline SRmA777 & $\mathrm{SRmA363} \exp A 1:: \operatorname{Tn} 5, \mathrm{Sm}^{\mathrm{r}}, \mathrm{Nm}^{\mathrm{r}}$ & This work \\
\hline $\operatorname{Rm} 7225$ & $\mathrm{Rm} 1021$ exoH::Tn5-233, $\mathrm{Sm}^{\mathrm{r}}, \mathrm{Gm}^{\mathrm{r}}$ & Leigh et al. 1987 \\
\hline SRmD445 & SRmA363 ехоH::Tn5-23,3 $\mathrm{Sm}^{\mathrm{r}}, \mathrm{Gm}^{\mathrm{r}}$ & This work \\
\hline $\operatorname{Rm} 8826$ & Rm1021 exsH::Tn5 exoK::Tn5-233, $\mathrm{Sm}^{\mathrm{r}}, \mathrm{Nm}^{\mathrm{r}}, \mathrm{Gm}^{\mathrm{r}}$ & York and Walker 1997 \\
\hline SRmD377 & $\mathrm{Rm} 1021 n d v B:: \operatorname{Tn} 5-233, \mathrm{Sm}^{\mathrm{r}}, \mathrm{Gm}^{\mathrm{r}}$ & J. Gonzalez \\
\hline Rm11482 & $\mathrm{Rm} 1021 \operatorname{glg} A 1 \Delta P s t \mathrm{I} g \lg A 2:: \Omega \mathrm{SpSm}, \mathrm{Sm}^{\mathrm{r}}, \mathrm{Sp}^{\mathrm{r}}$ & Wang et al. 2007 \\
\hline SRmD455 & $\mathrm{Rm} 7055 \operatorname{glg} A 1 \Delta$ PstI $\operatorname{glg} A 2:: \Omega \mathrm{SpSm}, \mathrm{Sm}^{\mathrm{r}}, \mathrm{Sp}^{\mathrm{r}}, \mathrm{Nm}^{\mathrm{r}}$ & This work \\
\hline SRmD456 & $\mathrm{Rm} 7055 n d v B:: \operatorname{Tn} 5-233, \mathrm{Sm}^{\mathrm{r}}, \mathrm{Nm}^{\mathrm{r}}, \mathrm{Gm}^{\mathrm{r}}$ & This work \\
\hline \multicolumn{3}{|l|}{ Escherichia coli } \\
\hline MM294A & Pro-82 this-1 hsdR17 supE44 & Finan et al. 1986 \\
\hline MT607 & MM294A; recA56 & Finan et al. 1986 \\
\hline MT616 & MT607(pRK600) & Finan et al. 1986 \\
\hline DH5 $\alpha$ & $\lambda^{-} \phi 80 \mathrm{~d} l a c Z^{\circ} \mathrm{M} 15^{\circ}\left(\right.$ lacZYA-argF)U169 recAl endA1 hsdR17( $\left.\mathrm{r}_{\mathrm{k}}^{-} \mathrm{m}_{\mathrm{k}}^{-}\right)$supE44 thi-1 gyrA relA1 & Hanahan 1983 \\
\hline \multicolumn{3}{|c|}{ 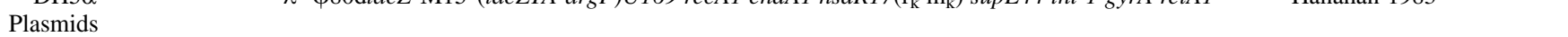 } \\
\hline pBluesciptII SK ${ }^{+}$ & Cloning vector ColE1 oriV Amp ${ }^{\mathrm{r}}$ & Stratagene \\
\hline pRK600 & pRK2013 npt::Tn9 $\mathrm{Cm}^{\mathrm{r}}$ & Finan et al. 1986 \\
\hline pMW22 & $\mathrm{Km}^{\mathrm{r}}$ fragment cloned as $\mathrm{SmaI}$ fragment into pBlueScript & Pickering and Oresnik 2008 \\
\hline pRK415 & $\mathrm{Tc}^{\mathrm{r}}$ IncP broad-host-range cloning vector & Keen et al. 1988 \\
\hline pPH1JI & IncP plasmid $\mathrm{Gm}^{\mathrm{r}}$ & Beringer 1974 \\
\hline pMW43 & expAl in pBluesciptII $\mathrm{SK}^{+}$ & This work \\
\hline pMW44 & $\mathrm{Km}^{\mathrm{r}}$ cassette from pMW22 cloned into expA1 in pMW43 & This work \\
\hline pMW45 & expA1:: $\mathrm{Km}^{\mathrm{r}}$ from pMW44 cloned into pRK415 & This work \\
\hline
\end{tabular}

${ }^{\mathrm{a}} \mathrm{Sm}^{\mathrm{r}}, \mathrm{Nm}^{\mathrm{r}}, \mathrm{Gm}^{\mathrm{r}}, \mathrm{Sp}^{\mathrm{r}}, \mathrm{Cm}^{\mathrm{r}}, \mathrm{Amp}^{\mathrm{r}}$, and $\mathrm{Km}^{\mathrm{r}}=$ resistance to streptomycin, neomycin, gentamicin, spectinomycin, chloramphenicol, ampicillin, and kanamycin, respectively. 
concentration of $15 \mathrm{mM}$. When required, medium was buffered using either $50 \mathrm{mM}$ MOPS or $50 \mathrm{mM}$ MES. Antibiotics were used as indicated for $S$. meliloti and Escherichia coli at the following concentrations: streptomycin, $200 \mu \mathrm{g} / \mathrm{ml}$; neomycin, $200 \mu \mathrm{g} / \mathrm{ml}$; and tetracycline, $5 \mu \mathrm{g} / \mathrm{ml}$. Gentamicin was used at $20 \mu \mathrm{g} / \mathrm{ml}$ for $E$. coli or $60 \mu \mathrm{g} / \mathrm{ml}$ for $S$. meliloti.

\section{DNA and genetic manipulations.}

Conjugations and transductions were carried out as previously described (Finan et al. 1984, 1988). Standard techniques for plasmid isolation, ligations, transformation, restrictions, and gel electrophoresis were used (Sambrook et al. 1989).

To construct a knockout of the gene $\operatorname{expAl}$ ( $w g a A)$, the gene was PCR-amplified from Rm1021 genomic DNA using primers expA1FW (HindIII site underlined) (5'-AGTCAAGCTT ATGTCTTCTAACGTGAGGCAG-3' and expA1RV (EcoRI site underlined) (5'-AGTCGGATCCTTATTTCCGGACATTGGACGC$\left.3^{\prime}\right)$ and was cloned into pBS SK ${ }^{+}$as a HindIII/BamHI fragment creating pMW43. Following this, the kanamycin cassette from pMM22 was isolated as a SmaI fragment and blunt end ligated into an EcoRI site in $\exp A 1$ yielding pMW44. The expAl fragment with the kanamycin cassette was then subcloned into pRK415 as a BamHI/KpnI fragment to create pMW45. pMW45 was subsequently conjugated into Rm1021, and integration of the mutation was carried out using pPH1JI, as previously described (Oresnik et al. 1998; Pickering and Oresnik 2008). The resulting mutation was verified by amplifying the insertion junctions by PCR and sequencing the resulting product. The expA1 mutation was subsequently transduced into Rm1021 or SRmA363, creating SRmA775 and SRmA777, respectively.

SRmD445 was created by transducing the exoH mutation from Rm7225 into SRmA363. Strains SRmD455 and SRmD456 were constructed by transducing the exoY mutation from Rm7055 into Rm11482 and SRmD377, respectively. Transductants were routinely single colony-purified three times before being used.

\section{RNA isolation, cDNA synthesis, and qRT-PCR.}

For bacterial RNA isolation, cultures were grown as described for polysaccharide isolation with minor modification (discussed below). Cultures were inoculated in $5 \mathrm{ml}$ of RMM with mannitol, and were subcultured into $50 \mathrm{ml}$ of MGS medium buffered at $\mathrm{pH} 5.75$ or $\mathrm{pH}$ 7. Cultures were grown overnight to midlog phase. A volume of $10 \mathrm{ml}$ of this culture was removed and was quenched using a 2:1 volume of Qiagen RNA protect. RNA was then extracted from the quenched cells using the Qiagen RNeasy kit, as previously described (Geddes et al. 2010). Approximately $200 \mathrm{ng}$ of cDNA was utilized as template for qRT-PCR. Reactions were performed using the SYBR green RT-PCR kit from Invitrogen, as indicated by the kit. RT-PCR reactions were performed as previously described (Geddes et al. 2010). The gene SMc00128, encoding a hypothetical protein, was utilized as an internal control for comparison of data sets (Krol and Becker 2004). Transcription of this gene was observed to not be influenced by $\mathrm{pH}$ in $\mathrm{Rm} 1021$, showing a mean cycle threshold value of 23.79 and 23.41 at $\mathrm{pH} 5.75$ and $\mathrm{pH} \mathrm{7,} \mathrm{re-}$ spectively. The RT-PCR primers used in this work are previously described (Geddes et al. 2014; Glenn et al. 2007; Hoang et al. 2008). Primers used but not previously described are as indicated in Supplementary Table S1.

\section{Isolation and quantification of EPS.}

Isolation of EPS, glycogen, and cyclic $\beta(1-2)$ glucans was carried out essentially as previously described, with modifications (Breedveld et al. 1993; Marroquí et al. 2001; Wang et al. 2007). Strains were grown for 1 day at $30^{\circ} \mathrm{C}$ in a volume of $50 \mathrm{ml}$ of RMM containing $15 \mathrm{mM}$ mannitol as a carbon source. Cultures were then resuspended in RMM to an optical density at $600 \mathrm{~nm}\left(\mathrm{OD}_{600}\right)$ of 0.1 , then, pelleted and washed twice with double distilled (dd) $\mathrm{H}_{2} \mathrm{O}$. The final pellet was then resuspended in $500 \mathrm{ml}$ of MGS buffered at either $\mathrm{pH} 5.75$, using $50 \mathrm{mM}$ MES, or $\mathrm{pH} 7$, using $50 \mathrm{mM}$ MOPS. Cells were then grown for 3 days at $30^{\circ} \mathrm{C}$. After 3 days, the $\mathrm{OD}_{600}$ of the cultures was determined. To facilitate pelleting of the cells, the culture was diluted 1:1 with $\mathrm{ddH}_{2} \mathrm{O}$. The supernatant was removed and used to determine the EPS, whereas the cell pellet was used for quantification of glycogen and cyclic $\beta(1-2)$ glucans.

To quantify EPS production, EPS was precipitated from the supernatant, using ethanol precipitation, as previously described (Marroquí et al. 2001). Essentially, the EPS was precipitated using $100 \%$ ethanol in a ratio of $2.5: 1$ with culture supernatant and was centrifuged at $20,000 \times g$ for $10 \mathrm{~min}$ at $4^{\circ} \mathrm{C}$ to pellet the EPS. The supernatant was decanted and the resulting pellet was dried at $40^{\circ} \mathrm{C}$ for $20 \mathrm{~min}$ and was then weighed. Weight of EPS was normalized to the $\mathrm{OD}_{600}$ of the culture. Student's $t$ test was used to determine significance of data.

Concentration of EPS-I in culture supernatant was also determined, using the Anthrone assay, as previously described (Morris 1948). The concentration of total reducing ends of EPS-I in culture supernatant was determined through the Lever assay and was compared with a glucose standard curve (Lever 1972). A ratio of the concentration of total EPS-I to the concentration of reducing ends was used to estimate the change in total chain length of EPS-I. The concentration of EPS was normalized to cell pellet weight.

\section{Glycogen and cyclic $\beta(1-2)$ glucan isolation and quantification.}

Isolated cell pellets were washed once with $10 \mathrm{ml}$ of $\mathrm{ddH}_{2} \mathrm{O}$ and were then resuspended in $1 \mathrm{M} \mathrm{KOH}$ and boiled at $100^{\circ} \mathrm{C}$ in a water bath for $20 \mathrm{~min}$, to allow for cell lysis. Cell debris was removed by centrifugation $(13,000 \mathrm{rpm}$ for $10 \mathrm{~min})$ and supernatant was removed to a new tube. Glycogen was precipitated, by the addition of $100 \%$ ethanol $1: 1$ ( vol/vol), and collected (Wang et al. 2007). The remaining supernatant was quantified for the presence of periplasmic cyclic $\beta(1-2)$ glucans (Breedveld et al. 1993). Quantification of glycogen and cyclic $\beta(1-2)$ glucans was carried out using the anthrone- $\mathrm{H}_{2} \mathrm{SO}_{4}$ method (Breedveld et al. 1990). Results were compared against a glucose standard curve. Concentrations are an average of three independent biological replicates. Concentrations were normalized to the weight of cell pellet used.

\section{Acidic pH tolerance.}

Cultures were started in $5 \mathrm{ml}$ of RMM with mannitol and were grown overnight at $30^{\circ} \mathrm{C}$. Cultures were then diluted to an $\mathrm{OD}_{600}$ of 0.1 in RMM. Then, $1 \mathrm{ml}$ of each culture was removed, was washed with $1 \mathrm{ml}$ of $\mathrm{ddH}_{2} \mathrm{O}$, and was resuspended in $1 \mathrm{ml}$ of saline $(0.85 \% \mathrm{wt} / \mathrm{vol})$. Cultures were then serial diluted from $10^{0}$ to $10^{-5}$ and $10 \mu \mathrm{l}$ of each dilution was spotted onto MGS agar plates buffered at either $\mathrm{pH} 5.75$ or $\mathrm{pH} 7$. Plates were then incubated at $30^{\circ} \mathrm{C}$ for 4 days and were then quantified by calculating CFU per milliliter. At pH 5.75, single colonies were not visible, so a dissecting microscope was utilized to count microcolonies to calculate CFUs per milliliter.

\section{Plant dry weights and competition for nodule occupancy.}

Alfalfa seeds were surface-sterilized with $1 \%$ bleach, were washed with at least 10 volumes of sterile $\mathrm{ddH}_{2} \mathrm{O}$, and were subsequently germinated on water agar plates for $48 \mathrm{~h}$ in the dark. Ten seedlings were then planted in sterile Leonard jars containing a 1:1 ratio of sand to vermiculite that had been soaked in nitrogen free Jensen's medium. After 2 days, seedlings were inoculated with approximately $10^{7} \mathrm{CFU}$ of bacteria in $10 \mathrm{ml}$ of water. Nodule occupancy and plant dry weights were 
determined after 30 days. Plant dry weights are an average of three independent biological replicates consisting of 10 plants each. Nodule competition was determined, as previously described (Poysti and Oresnik 2007), by comparing the ratio of the mutant strain to wild type found in the inoculum to the same ratio found in isolated nodules. Numbers are an average of three independent biological replicates consisting of 50 examined nodules each.

\section{Nodule kinetics.}

Sterile alfalfa seedlings were planted on slants containing $10 \mathrm{ml}$ of Jensen's agar. After 2 days, slants were inoculated with $10^{6}$ bacteria in $100 \mu \mathrm{l}$ of water as described above. The rate of nodule formation was assessed over a period of 21 days. Numbers are an average of five independent biological replicates consisting of 10 plants each.

\section{ACKNOWLEDGMENTS}

This work was funded by a Natural Sciences and Engineering Research Council of Canada (NSERC) Discovery grant awarded to I. J. Oresnik. J. P. Hawkins acknowledges support from the University of Manitoba Faculty of Science Award and the University of Manitoba Faculty of Graduate Studies Graduate Enhancement of Tri-Council Stipends program. B. A. Geddes acknowledges funding in the form of an NSERC Canada Graduate Scholarships-Doctoral award.

\section{LITERATURE CITED}

Aneja, P., Dai, M., Lacorre, D. A., Pillon, B., and Charles, T. C. 2004. Heterologous complementation of the exopolysaccharide synthesis and carbon utilization phenotypes of Sinorhizobium meliloti Rm1021 polyhydroxyalkanoate synthesis mutants. FEMS Microbiol. Lett. 239:277-283.

Becker, A., Kleickmann, A., Keller, M., Arnold, W., and Pühler, A. 1993a. Identification and analysis of the Rhizobium meliloti exoA$M O N P$ genes involved in exopolysaccharide biosynthesis and mapping of promoters located on the exoHKLAMONP fragment. Mol. Gen. Genet. 241:367-379.

Becker, A., Kleickmann, A., Küster, H., Keller, M., Arnold, W., and Pühler, A. 1993b. Analysis of the Rhizobium meliloti genes exoU, exoV, exoW, exoT, and exoI involved in exopolysaccharide biosynthesis and nodule invasion: exoU and exoW probably encode glucosyltransferases. Mol. Plant-Microbe Interact. 6:735-744.

Becker, A., Niehaus, K., and Pühler, A. 1995. Low-molecular-weigh succinoglycan is predominantly produced by Rhizobium meliloti strains carrying a mutated ExoP protein characterized by a periplasmic $\mathrm{N}$-terminal domain and a missing C-terminal domain. Mol. Microbiol. 16:191-204.

Becker, A., Rüberg, S., Küster, H., Roxlau, A. A., Keller, M., Ivashina, T., Cheng, H.-P., Walker, G. C., and Pühler, A. 1997. The 32-kilobase exp gene cluster of Rhizobium meliloti directing the biosynthesis of galactoglucan: Genetic organization and properties of the encoded gene products. J. Bacteriol. 179:1375-1384.

Beringer, J. E. 1974. R factor transfer in Rhizobium leguminosarum. J. Gen Microbiol. 84:188-198.

Bibikova, T. N., Jacob, T., Dahse, I., and Gilroy, S. 1998. Localized changes in apoplastic and cytoplasmic $\mathrm{pH}$ are associated with root hair development in Arabidopsis thaliana. Development 125:2925-2934.

Breedveld, M. W., Cremers, H. C., Batley, M., Posthumus, M. A., Zevenhuizen, L. P. T. M., Wijffelman, C. A., and Zehnder, A. J. B. 1993. Polysaccharide synthesis in relation to nodulation behavior of Rhizobium leguminosarum. J. Bacteriol. 175:750-757.

Breedveld, M. W., Zevenhuizen, L. P. T. M., and Zehnder, A. J. B. 1990. Osmotically induced oligo- and polysaccaride synthesis by Rhizobium meliloti SU-47. J. Gen. Microbiol. 136:2511-2519.

Broughton, W. J., Wong, C. H., Lewin, A., Samrey, U., Myint, H., Meyer, H., Dowling, D. N., and Simon, R. 1986. Identification of Rhizobium plasmid sequences involved in recognition of Psophocarpus, Vigna, and other legumes. J. Cell Biol. 102:1173-1182.

Chen, E. J., Sabio, E. A., and Long, S. R. 2008. The periplasmic regulator ExoR inhibits ExoS/ChvI two-component signalling in Sinorhizobium meliloti. Mol. Microbiol. 69:1290-1303.

Chen, H., Richardson, A. E., and Rolfe, B. G. 1993. Studies of the physiological and genetic basis of acid tolerance in Rhizobium leguminosarum biovar trifolii. Appl. Environ. Microbiol. 59:1798-1804.
Cheng, H.-P., and Walker, G. C. 1998a. Succinoglycan is required for initiation and elongation of infection threads during nodulation of alfalfa by Rhizobium meliloti. J. Bacteriol. 180:5183-5191.

Cheng, H.-P., and Walker, G. C. 1998b. Succinoglycan production by Rhizobium meliloti is regulated through the ExoS-ChvI two-componen regulatory system. J. Bacteriol. 180:20-26.

Cieśla, J., Kopycińska, M., Łukowska, M., Bieganowski, A., and Janczarek, M. 2016. Surface properties of wild-type Rhizobium leguminosarum bv. trifolii strain 24.2 and Its derivatives with different extracellular polysaccharide content. PLoS One 11:e0165080.

Cunningham, S. D., and Munns, D. N. 1984. The correlation between extracellular polysaccharide production and acid tolerance in Rhizobium. Soil Sci. Soc. Am. J. 48:1273-1277.

Donati, A. J., Jeon, J. M., Sangurdekar, D., So, J. S., and Chang, W. S. 2011 Genome-wide transcriptional and physiological responses of Bradyrhizobium japonicum to paraquat-mediated oxidative stress. Appl. Environ. Microbiol. 77:3633-3643.

Draghi, W. O., Del Papa, M. F., Barsch, A., Albicoro, F. J., Lozano, M. J., Pühler, A., Niehaus, K., and Lagares, A. 2017. A metabolomic approach to characterize the acid-tolerance response in Sinorhizobium meliloti. Metabolomics 13:71

Dunn, M. F., Araíza, G., Encarnación, S., Vargas, C., Mora, J., and Ara1, G. 2002. Effect of aniA (carbon flux regulator) and and phaC (poly$\beta$-hydroxybutyrate synthase) mutations on pyruvate metabolism in Rhizobium etli. J. Bacteriol. 184:2296-2299.

Dylan, T., Helinski, D. R., and Ditta, G. S. 1990. Hypoosmotic adaptation in Rhizobium meliloti requires beta-(1----2)-glucan. J. Bacteriol. 172. 1400-1408.

Faget, M., Blossfeld, S., von Gillhaussen, P., Schurr, U., and Temperton, V. M. 2013. Disentangling who is who during rhizosphere acidification in root interactions: Combining fluorescence with optode techniques. Front. Plant Sci. 4:392.

Fedorova, E., Thomson, R., Whitehead, L. F., Maudoux, O., Udvardi, M. K., and Day, D. A. 1999. Localization of $\mathrm{H}^{+}$-ATPases in soybean root nodules. Planta 209:25-32.

Ferguson, B. J., Lin, M.-H., and Gresshoff, P. M. 2013. Regulation of legume nodulation by acidic growth conditions. Plant Signal. Behav. 8:e23426.

Finan, T. M., Hartweig, E., LeMieux, K., Bergman, K., Walker, G. C., and Signer, E. R. 1984. General transduction in Rhizobium meliloti. J. Bacteriol. 159:120-124.

Finan, T. M., Kunkel, B., De Vos, G. F., and Signer, E. R. 1986. Second symbiotic megaplasmid in Rhizobium meliloti carrying exopolysaccharide and thiamine synthesis genes. J. Bacteriol. 167:66-72.

Finan, T. M., Oresnik, I., and Bottacin, A. 1988. Mutants of Rhizobium meliloti defective in succinate metabolism. J. Bacteriol. 170:3396-3403.

Geddes, B. A., González, J. E., and Oresnik, I. J. 2014. Exopolysaccharide production in response to medium acidification is correlated with an increase in competition for nodule occupancy. Mol. Plant-Microbe Interact. 27:1307-1317.

Geddes, B. A., and Oresnik, I. J. 2016. The mechanism of symbiotic nitrogen fixation. Pages 69-97 in: The Mechanistic Benefits of Microbial Symbionts, Advances in Environmental Microbiology Vol. 2, C. J. Hurst, ed. Springer International Publishing, Cham, Switzerland.

Geddes, B. A., Pickering, B. S., Poysti, N. J., Collins, H., Yudistira, H., and Oresnik, I. J. 2010. A locus necessary for the transport and catabolism of erythritol in Sinorhizobium meliloti. Microbiology 156:2970-2981.

Glazebrook, J., and Walker, G. C. 1989. A novel exopolysaccharide can function in place of the calcofluor-binding exopolysaccharide in nodulation of alfalfa by Rhizobium meliloti. Cell 56:661-672.

Glenn, S. A., Gurich, N., Feeney, M. A., and González, J. E. 2007. The ExpR/Sin quorum-sensing system controls succinoglycan production in Sinorhizobium meliloti. J. Bacteriol. 189:7077-7088.

González, J. E., Semino, C. E., Wang, L. X., Castellano-Torres, L. E., and Walker, G. C. 1998. Biosynthetic control of molecular weight in the polymerization of the octasaccharide subunits of succinoglycan, a symbiotically important exopolysaccharide of Rhizobium meliloti. Proc. Natl. Acad. Sci. U.S.A. 95:13477-13482.

Hanahan, D. 1983. Studies on transformation of Escherichia coli with plasmids. J. Mol. Biol. 166:557-580.

Hawkins, J. P., and Oresnik, I. J. 2017. Characterisation of a gene encoding a membrane protein that affects exopolysaccharide production and intracellular Mg2+ concentrations in Ensifer meliloti. FEMS Microbiol. Lett. 364:1-7.

Heavner, M. E., Qiu, W. G., and Cheng, H. P. 2015. Phylogenetic co-occurrence of ExoR, ExoS, and ChvI, components of the RSI bacterial invasion switch, suggests a key adaptive mechanism regulating the transition between freeliving and host-invading phases in Rhizobiales. PLoS One 10:e0135655.

Heckel, B. C., Tomlinson, A. D., Morton, E. R., Choi, J. H., and Fuqua, C. 2014. Agrobacterium tumefaciens exoR controls acid response genes and 
impacts exopolysaccharide synthesis, horizontal gene transfer, and virulence gene expression. J. Bacteriol. 196:3221-3233.

Hellweg, C., Pühler, A., and Weidner, S. 2009. The time course of the transcriptomic response of Sinorhizobium meliloti 1021 following a shift to acidic pH. BMC Microbiol. 9:37.

Her, G. R., Glazebrook, J., Walker, G. C., and Reinhold, V. N. 1990. Structural studies of a novel exopolysaccharide produced by a mutant of Rhizobium meliloti strain Rm1021. Carbohydr. Res. 198:305-312.

Herridge, D. F., Peoples, M. B., and Boddey, R. M. 2008. Global inputs of biological nitrogen fixation in agricultural systems. Plant Soil 311:1-18.

Hoang, H. H., Gurich, N., and González, J. E. 2008. Regulation of motility by the ExpR/Sin quorum-sensing system in Sinorhizobium meliloti. J. Bacteriol. 190:861-871.

Howieson, J. G., Ewing, M. A., and D'Antuono, M. F. 1988. Selection for acid tolerance in Rhizobium meliloti. Plant Soil 105:179-188.

Jones, K. M. 2012. Increased production of the exopolysaccharide succinoglycan enhances Sinorhizobium meliloti 1021 symbiosis with the host plant Medicago truncatula. J. Bacteriol. 194:4322-4331.

Jones, K. M., Kobayashi, H., Davies, B. W., Taga, M. E., and Walker, G. C. 2007. How rhizobial symbionts invade plants: The SinorhizobiumMedicago model. Nat. Rev. Microbiol. 5:619-633.

Jones, K. M., and Walker, G. C. 2008. Responses of the model legume Medicago truncatula to the rhizobial exopolysaccharide succinoglycan. Plant Signal. Behav. 3:888-890.

Kawaharada, Y., Kelly, S., Nielsen, M. W., Hjuler, C. T., Gysel, K., Muszyński, A., Carlson, R. W., Thygesen, M. B., Sandal, N., Asmussen, M. H., Vinther, M., Andersen, S. U., Krusell, L., Thirup, S., Jensen, K. J., Ronson, C. W., Blaise, M., Radutoiu, S., and Stougaard, J. 2015. Receptor-mediated exopolysaccharide perception controls bacterial infection. Nature 523: 308-312.

Keen, N. T., Tamaki, S., Kobayashi, D., and Trollinger, D. 1988. Improved broad-host-range plasmids for DNA cloning in gram-negative bacteria. Gene 70:191-197.

Kereszt, A., Kiss, E., Reuhs, B. L., Carlson, R. W., Kondorosi, A., and Putnoky, P. 1998. Novel rkp gene clusters of Sinorhizobium meliloti involved in capsular polysaccharide production and invasion of the symbiotic nodule: The $r k p K$ gene encodes a UDP-glucose dehydrogenase. J. Bacteriol. 180: 5426-5431.

Krol, E., and Becker, A. 2004. Global transcriptional analysis of the phosphate starvation response in Sinorhizobium meliloti strains 1021 and 2011. Mol. Genet. Genomics 272:1-17.

Lehman, A. P., and Long, S. R. 2013. Exopolysaccharides from Sinorhizobium meliloti can protect against $\mathrm{H}_{2} \mathrm{O}_{2}$-dependent damage. J. Bacteriol. 195: 5362-5369.

Leigh, J. A., and Lee, C. C. 1988. Characterization of polysaccharides of Rhizobium meliloti exo mutants that form ineffective nodules. J. Bacteriol. 170:3327-3332.

Leigh, J. A., Reed, J. W., Hanks, J. F., Hirsch, A. M., and Walker, G. C. 1987. Rhizobium meliloti mutants that fail to succinylate their calcofluor-binding exopolysaccharide are defective in nodule invasion. Cell 51:579-587.

Leigh, J. A., Signer, E. R., and Walker, G. C. 1985. Exopolysaccharidedeficient mutants of Rhizobium meliloti that form ineffective nodules. Proc. Natl. Acad. Sci. U.S.A. 82:6231-6235.

Lever, M. 1972. A new reaction for colorimetric determination of carbohydrates. Anal. Biochem. 47:273-279.

Li, L., Jia, Y., Hou, Q., Charles, T. C., Nester, E. W., and Pan, S. Q. 2002. A global pH sensor: Agrobacterium sensor protein $\mathrm{ChvG}$ regulates acidinducible genes on its two chromosomes and Ti plasmid. Proc. Natl. Acad. Sci. U.S.A. 99:12369-12374.

Lowendorf, H. S., Baya, A. M., and Alexander, M. 1981. Survival of Rhizobium in acid soils. Appl. Environ. Microbiol. 42:951-957.

Lu, H. Y., Luo, L., Yang, M. H., and Cheng, H.-P. 2012. Sinorhizobium meliloti ExoR is the target of periplasmic proteolysis. J. Bacteriol. 194: 4029-4040.

Marroquí, S., Zorreguieta, A., Santamaría, C., Temprano, F., Soberón, M., Megías, M., and Downie, J. A. 2001. Enhanced symbiotic performance by Rhizobium tropici glycogen synthase mutants. J. Bacteriol. 183:854-864.

Meade, H. M., Long, S. R., Ruvkun, G. B., Brown, S. E., and Ausubel, F. M. 1982. Physical and genetic characterization of symbiotic and auxotrophic mutants of Rhizobium meliloti induced by transposon Tn5 mutagenesis. J. Bacteriol. 149:114-122.

Mendis, H. C., Madzima, T. F., Queiroux, C., and Jones, K. M. 2016. Function of succinoglycan polysaccharide in Sinorhizobium meliloti host plant invasion depends on succinylation, not molecular weight. MBio 7:e00606-16.

Mendrygal, K. E., and González, J. E. 2000. Environmental regulation of exopolysaccharide production in Sinorhizobium meliloti. J. Bacteriol. 182:599-606.
Miller-Williams, M., Loewen, P. C., and Oresnik, I. J. 2006. Isolation of salt-sensitive mutants of Sinorhizobium meliloti strain Rm1021. Microbiology 152:2049-2059.

Morris, D. L. 1948. Quantitative determination of carbohydrates with Dreywood's anthrone reagent. Science 107:254-255.

Müller, M. G., Forsberg, L. S., and Keating, D. H. 2009. The $r k p-1$ cluster is required for secretion of Kdo homopolymeric capsular polysaccharide in Sinorhizobium meliloti strain Rm1021. J. Bacteriol. 191:6988-7000.

Nagpal, P., Khanuja, S. P., and Stanfield, S. W. 1992. Suppression of the ndv mutant phenotype of Rhizobium meliloti by cloned exo genes. Mol. Microbiol. 6:479-488.

Oldroyd, G. E. D. 2013. Speak, friend, and enter: Signalling systems that promote beneficial symbiotic associations in plants. Nat. Rev. Microbiol. 11:252-263.

Oresnik, I. J., Charles, T. C., and Finan, T. M. 1994. Second site mutations specifically suppress the Fix- phenotype of Rhizobium meliloti $n d v F$ mutations on alfalfa: Identification of a conditional $n d v F$-dependent mucoid colony phenotype. Genetics 136:1233-1243.

Oresnik, I. J., Pacarynuk, L. A., O’Brien, S. A. P., Yost, C. K., and Hynes, M. F. 1998. Plasmid-encoded catabolic genes in Rhizobium leguminosarum bv. trifolii: Evidence for a plant-inducible rhamnose locus involved in competition for nodulation. Mol. Plant-Microbe Interact. 11:1175-1185.

Pellock, B. J., Cheng, H. P., and Walker, G. C. 2000. Alfalfa root nodule invasion efficiency is dependent on Sinorhizobium meliloti polysaccharides. J. Bacteriol. 182:4310-4318.

Pickering, B. S., and Oresnik, I. J. 2008. Formate-dependent autotrophic growth in Sinorhizobium meliloti. J. Bacteriol. 190:6409-6418.

Pierre, O., Engler, G., Hopkins, J., Brau, F., Boncompagni, E., and Hérouart, D. 2013. Peribacteroid space acidification: A marker of mature bacteroid functioning in Medicago truncatula nodules. Plant Cell Environ. 36: 2059-2070.

Povolo, S., and Casella, S. 2000. A critical role for aniA in energy-carbon flux and symbiotic nitrogen fixation in Sinorhizobium meliloti. Arch. Microbiol. 174:42-49.

Poysti, N. J., and Oresnik, I. J. 2007. Characterization of Sinorhizobium meliloti triose phosphate isomerase genes. J. Bacteriol. 189:3445-3451.

Reinhold, B. B., Chan, S. Y., Reuber, T. L., Marra, A., Walker, G. C., and Reinhold, V. N. 1994. Detailed structural characterization of succinoglycan, the major exopolysaccharide of Rhizobium meliloti Rm1021. J. Bacteriol. 176:1997-2002.

Reuber, T. L., Long, S., and Walker, G. C. 1991. Regulation of Rhizobium meliloti exo genes in free-living cells and in planta examined by using TnphoA fusions. J. Bacteriol. 173:426-434.

Sambrook, J., Fritsch, E. F., and Mantiatis, T. L. 1989. Molecular Cloning: A Laboratory Manual, 2nd ed. Cold Spring Harbor Laboratory Press, Cold Spring Harbor, NY, U.S.A.

Skorupska, A., Janczarek, M., Marczak, M., Mazur, A., and Król, J. 2006. Rhizobial exopolysaccharides: Genetic control and symbiotic functions. Microb. Cell Fact. 5:7.

Szewczuk-Karpisz, K., Wiśniewska, M., Pac, M., Choma, A., and Komaniecka, I. 2014. Sinorhizobium meliloti 1021 exopolysaccharide as a flocculant improving chromium(III) oxide removal from aqueous solutions. Water Air Soil Pollut. 225:2052-2067.

Tiwari, R. P., Reeve, W. G., Dilworth, M. J., and Glenn, A. R. 1996. Acid tolerance in Rhizobium meliloti strain WSM419 involves a twocomponent sensor-regulator system. Microbiology 142:1693-1704.

von Uexküll, H. R., and Mutert, E. 1995. Global extent, development and economic-impact of acid soils. Plant Soil 171:1-15.

Wang, C., Kemp, J., Da Fonseca, I. O., Equi, R. C., Sheng, X., Charles, T. C., and Sobral, B. W. S. 2010. Sinorhizobium meliloti 1021 loss-offunction deletion mutation in $c h v I$ and its phenotypic characteristics. Mol. Plant-Microbe Interact. 23:153-160.

Wang, C., Saldanha, M., Sheng, X., Shelswell, K. J., Walsh, K. T., Sobral, B. W. S., and Charles, T. C. 2007. Roles of poly-3-hydroxybutyrate (PHB) and glycogen in symbiosis of Sinorhizobium meliloti with Medicago sp. Microbiology 153:388-398.

Yao, S. Y., Luo, L., Har, K. J., Becker, A., Rüberg, S., Yu, G. Q., Zhu, J. B., and Cheng, H. P. 2004. Sinorhizobium meliloti ExoR and ExoS proteins regulate both succinoglycan and flagellum production. J. Bacteriol. 186: 6042-6049.

York, G. M., and Walker, G. C. 1997. The Rhizobium meliloti exoK gene and prsD/prsE/exsH genes are components of independent degradative pathways which contribute to production of low-molecular-weight succinoglycan. Mol. Microbiol. 25:117-134.

York, G. M., and Walker, G. C. 1998. The Rhizobium meliloti ExoK and ExsH glycanases specifically depolymerize nascent succinoglycan chains. Proc. Natl. Acad. Sci. U.S.A. 95:4912-4917.

Zevenhuizen, L. P. T. M. 1981. Cellular glycogen, $\beta-1,2$,-glucan, poly $\beta$-hydroxybutyric acid and extracellular polysaccharides in fastgrowing species of Rhizobium. Antonie van Leeuwenhoek 47:481-497. 